\title{
Modified Mercalli Intensity for Scenario Earthquakes in Evansville, Indiana
} By Chris Cramer, Jennifer Haase, and Oliver Boyd

Evansville has experienced minor damage from earthquakes several times in the past 200 years. Because of this history and the fact that Evansville is close to the Wabash Valley and New result of an earthquake. Earthquake-hazard maps provide one way of conveying such estimates of strong ground shaking and will help the region prepare for future earthquakes and reduce earthquake-caused losses.
The Evansville Area Earthquake Hazards Mapping Project has produced a series of maps that show the hazards from earthquakes in the region. Included in this array of products are scenario-
hazard maps, which predict ground shaking from two hypothetical earthquakes: (1) a magnitude 7.7 earthquake in the New Madrid seismic zone, and (2) a magnitude 6.8 earthquake in the Wabash Valley seismic zone. These earthquakes are believed to be the largest probable earthquakes that could impact the Evansville region. The results from hescenario ground-motion modeling are displayed below in terms of Modified Mercallil Intensities (MM); the translation from ground-motion measurement to a description heavy damage). For both scenarios, the s While both scenarios predict at least some damage across the broader Evansville region, the level of damage is greater for the magnitude 6.8 Wabash Valley earthquake due to the proximity of Evanssvile to the earthquake source 25 miles versus 10 miles for New Madrid). scenario, light damage is expected outside of the river valley including broken windows and glassware and cracked plaster. Within the Ohio River valley, poorly designed masonry structures and adobe houses could be cracked and damaged, and weak chimneys may be broken.

These scenario ground-shaking maps complement probabilistic seismic-hazard maps produced by the Evansville Area Earthquake Hazard Mapping Group and provide government official

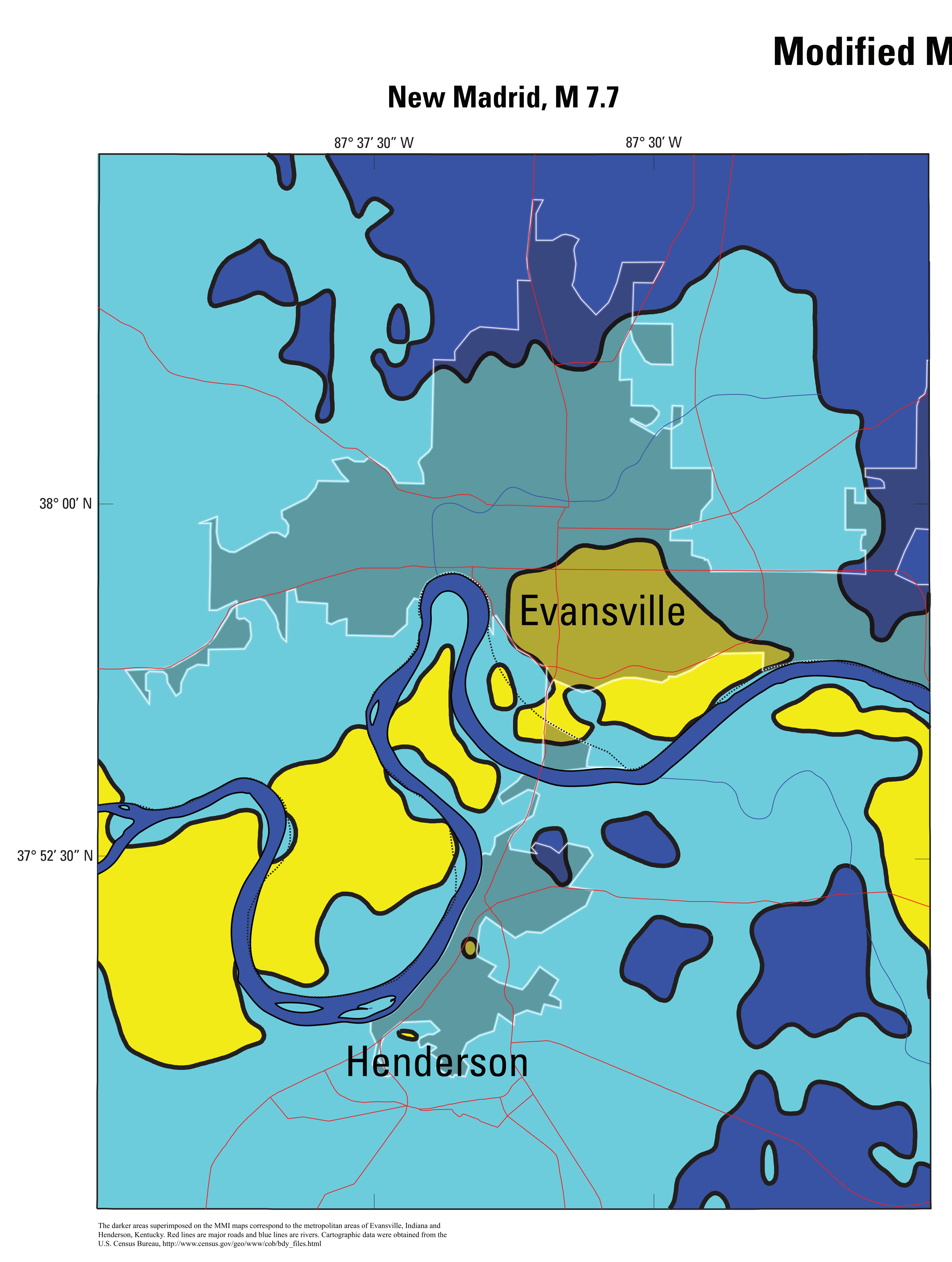

\section{calli Intensities}
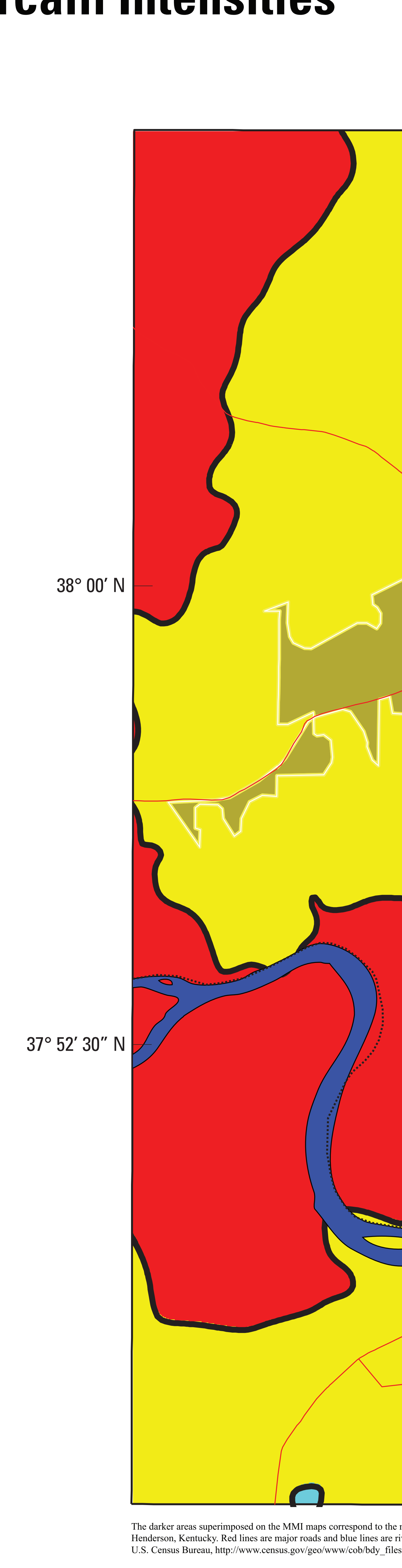

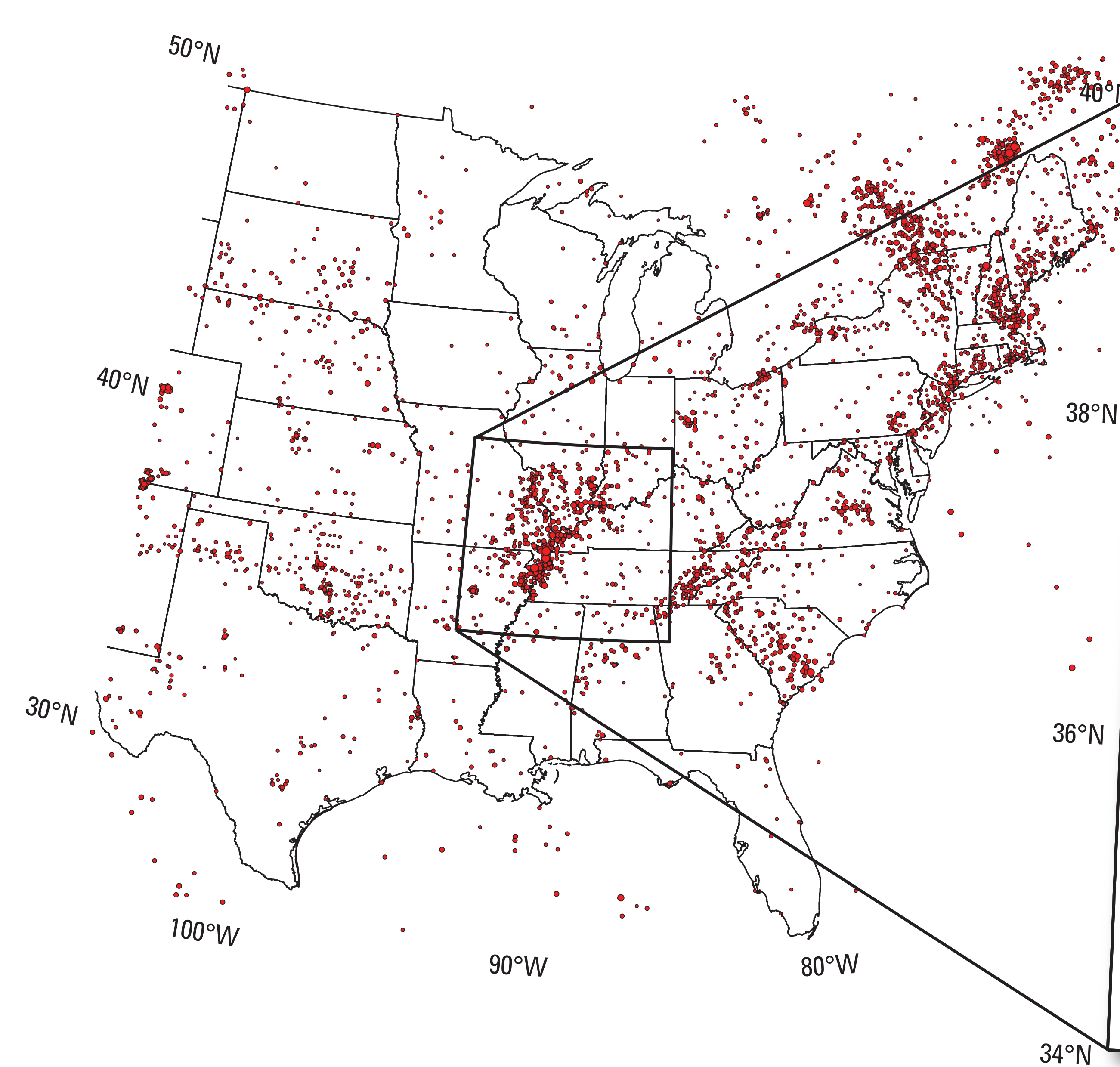

Wabash Valley, M 6.8

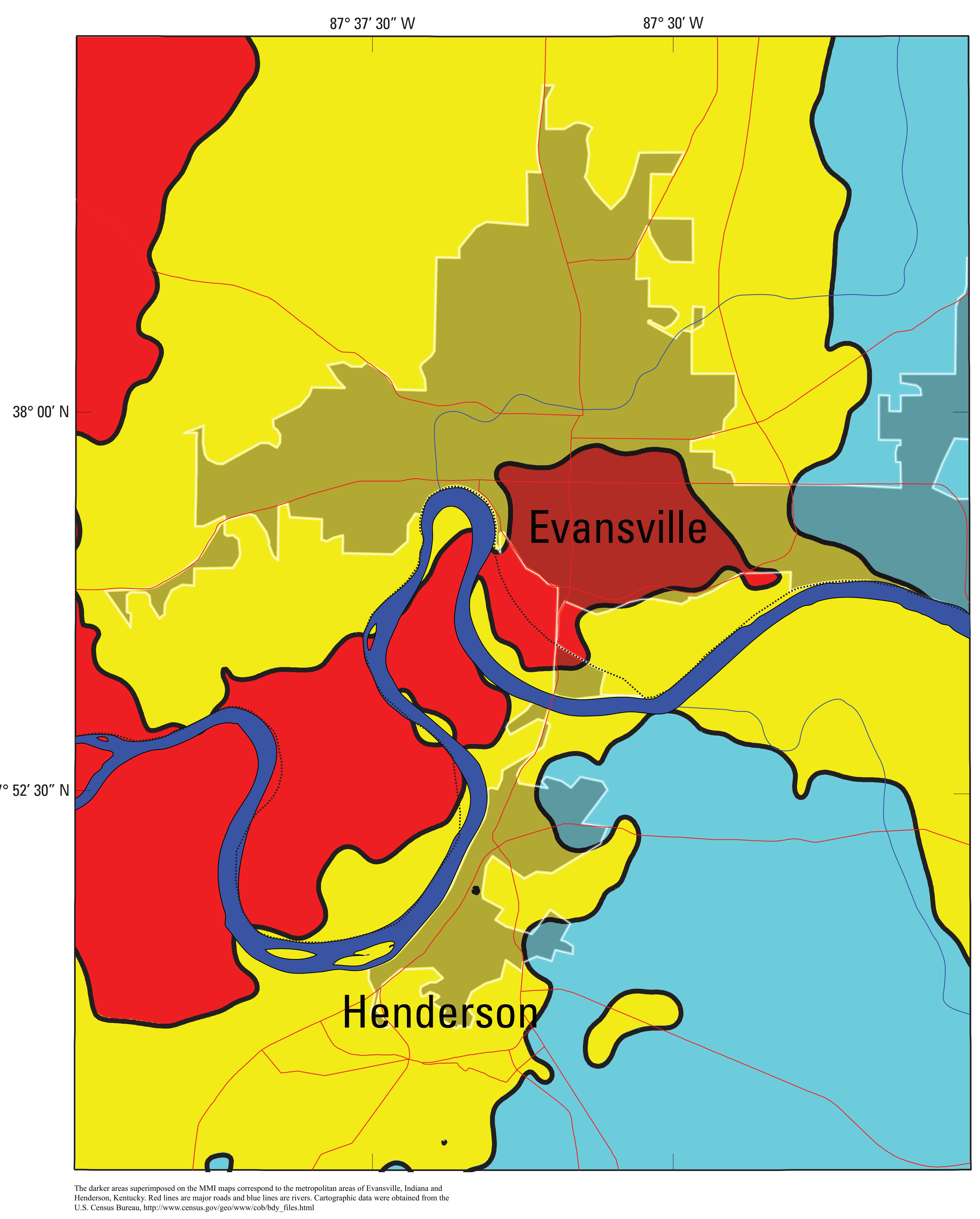

Earthquake Sources

Earthquakes in the image on the left are taken from the USGS earthquake cata-
log for the Nations 153 th 2 kos hat have oc

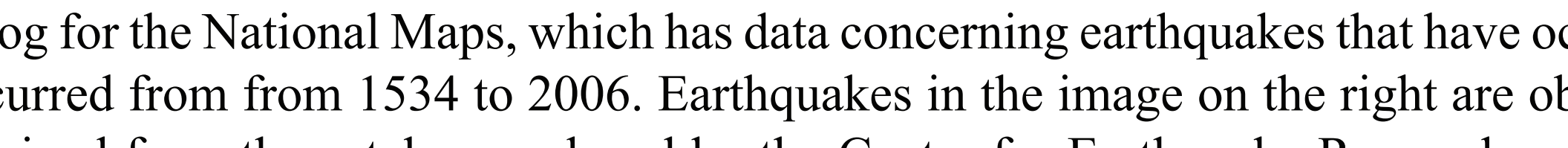

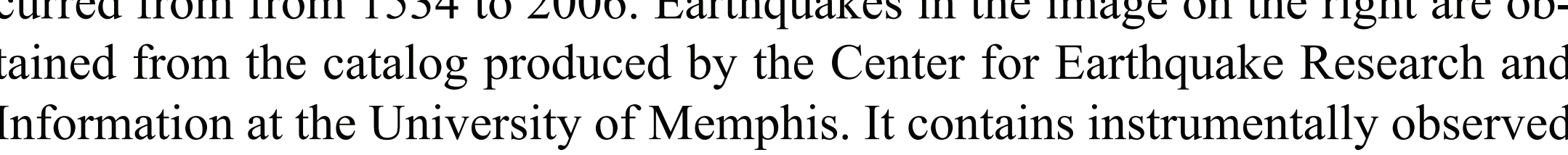
earthquakes
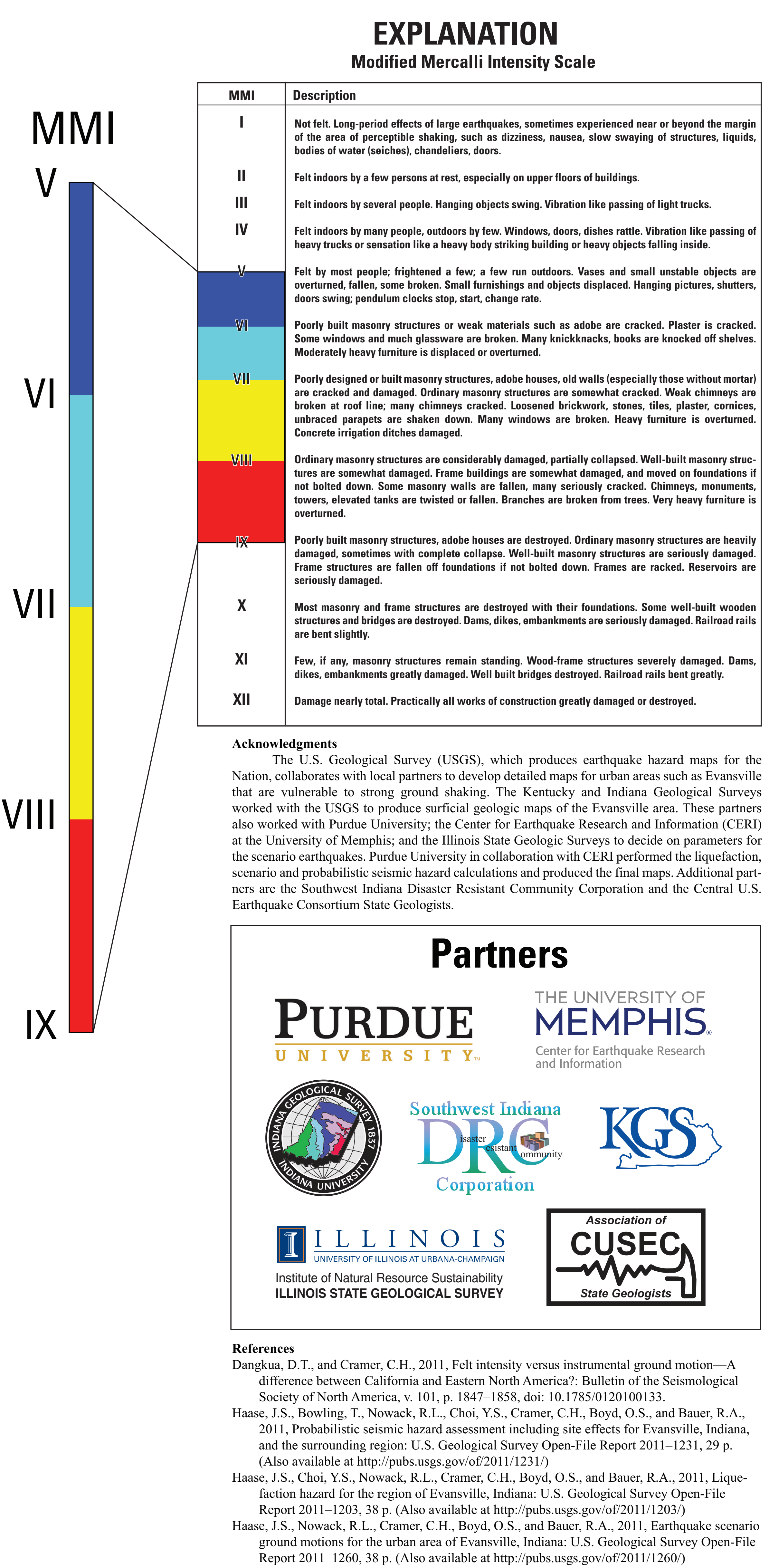